\title{
Complementary and alternative medicine in US medical schools
}

This article was published in the following Dove Press journal:

Advances in Medical Education and Practice

12 February 2015

Number of times this article has been viewed

\section{Virginia S Cowen' \\ Vicki Cyr ${ }^{2}$}

'Rutgers School of Health Related Professions Institute for Complementary and Alternative Medicine, Newark, NJ, USA;

${ }^{2}$ Department of Interdisciplinary Studies at the Rutgers University School of Health Related Professions, Newark, NJ, USA
Correspondence: Virginia S Cowen Rutgers University School of Health Related Professions, Institute for Complementary and Alternative Medicine, 65 Bergen Street, Box 1709, Newark, NJ 07107, USA

$\mathrm{Tel}+\mathrm{I} 9739728640$

Fax +l 9739725572

Email cowenvs@shrp.rutgers.edu

\begin{abstract}
An analysis of complementary and alternative medicine (CAM) in US medical school curriculum was undertaken. Websites for 130 US medical schools were systematically analyzed for course listings and content. Half of the schools (50.8\%) offered at least one CAM course or clerkship. A total of 127 different course listings were identified, embracing a range of topics and methods of instruction. The most frequently listed topics were traditional medicine, acupuncture, spirituality, and herbs, along with the general topic of CAM. Nearly $25.0 \%$ of the courses referenced personal growth or self-care through CAM practices, while only $11.0 \%$ referenced inter-professional education activities involving interaction with CAM providers. The most frequently reported instructional methods were lectures, readings, and observation of, or receiving a CAM treatment. The findings of this analysis indicated fewer medical schools offered instruction in CAM than previously reported and a wide range of approaches to the topic across the schools where CAM is taught.
\end{abstract}

Keywords: complementary and alternative medicine, CAM, medical education, curriculum

\section{Overview}

In the early 20th century, the Flexner Report identified inconsistencies in medical education among US medical schools. The findings of this report set the stage for standardization of conventional medical education emphasizing biomedical science, technology, pharmacology, and the scientific method. Therapeutic approaches that were alternative and deemed non-biomedical were excluded from the medical education curriculum. ${ }^{1}$ The 1970 s marked a resurgence in public interest in natural, holistic, and exotic therapies in the US ${ }^{2}$ and professionalization efforts across a number of alternative fields including massage therapy, naturopathy, and acupuncture followed. Subsequent surveys of US adults revealed large numbers of patients utilizing alternative therapies along with the revelation that patients did not generally discuss alternative therapy use with their physician. ${ }^{3,4}$

Education about complementary and alternative medicine (CAM) crept back into the medical school curriculum. CAM is not a single approach. Thus it is often described in exclusionary terms by what it is not: therapeutic approaches that are not part of the predominant biomedical system or topics not customarily included in medical education. ${ }^{3,4}$ Various suggestions for why knowledge about CAM is relevant for future physicians have been put forth. It has been suggested that learning about CAM therapies may foster positive attitudes about CAM. ${ }^{5,6}$ General knowledge about the theories and foundational practices of popular CAM therapies could help physicians' better counsel patients about health choices..$^{7-9}$ Study of evidence-based CAM treatments 
may help physicians feel better equipped to make referrals for CAM. ${ }^{10}$ Yet referrals to licensed CAM providers are not required for treatments and insurance reimbursement in the US and other referrals for CAM treatment may potentially carry some liability. ${ }^{10}$ Experiencing treatment with a CAM therapy and utilizing CAM modalities for self-care may be useful to improve empathy and cultural competence among medical students. ${ }^{9}$ However, there are questions about the effectiveness of CAM treatments and potential risks to patient health, introducing ethical questions regarding the teaching of CAM to medical students particularly when it involves participation or receiving treatment. ${ }^{10}$

Previous surveys indicated that $64 \%{ }^{11}$ and $84 \%{ }^{12}$ of medical schools provided CAM-related instruction. The range in these reports, published respectively in 1998 and 2002, along with representation of a limited number of medical schools suggested that follow-up investigation on CAM in the medical curriculum was needed. The availability of medical school course catalogs and curriculum on the internet presented an opportunity to obtain objective data. ${ }^{13,14}$ To explore what is being taught about CAM and how it is being taught in US medical schools, a systematic analysis of publicly-available information was undertaken. The purpose of this project was to present an overview of CAM taught at US medical schools.

\section{Methods}

This project employed a systematic approach to content analysis. The aim was to identify the extent to which CAM was taught in US medical schools and further explore whether there was a consistency to the topics and instructional methods used in the courses. The target data were course titles and descriptions in course catalogs of US medical schools. A list of 130 US medical schools was obtained through the Association of American Medical Colleges website in June 2012. US medical schools that confer Medical Doctor (MD) degrees were included in this analysis. Canadian and Caribbean medical schools as well as osteopathic and naturopathic medical schools were excluded. Because the focus of this analysis was undergraduate medical education, fellowships, residencies, and continuing medical education training, and courses for other types of health care professionals (non-MDs) were excluded from this analysis.

Medical school course catalogs, curriculum, and general websites were systematically searched between July 2012 and July 2013. The search strategy initially focused on the curriculum area for the MD degree from each medical school's website. The course catalog was searched for references to "CAM", "alternative", "complementary", "integrative", "mind-body", and "holistic". Any course listing was selected for inclusion if there were references to any of these terms, or CAM modalities in the course title or the course description. All available information about these courses was abstracted into a database and subsequently coded. Information for content on courses (didactic) and clerkships were pooled treating each course as a single case. This permitted analysis of all courses when multiple courses were listed at a single medical school. Because this analysis was exploratory, variables that would be used in analysis were not pre-determined. Once compiled, the dataset was analyzed for content as well as frequency of inclusion of information. Four general elements emerged: the topics of the courses, focus of course content for self-care or patient care, inter-professional education with CAM providers, and methods of instruction/assessment.

Data were analyzed using descriptive analyses in SPSS version 20 .

This project was reviewed and approved as an exempt protocol by the Rutgers University, Biomedical and Health Sciences Newark Campus, Human Subjects Institutional Review Board.

\section{Results}

Information on courses and curriculum was accessible on the internet for 125 medical schools (96.2\% of total.) CAM-related content was found in didactic courses and clerkships at 66 schools $(50.8 \%)$. A total of 127 courses and clerkships were identified across the 66 medical schools that provided any CAM instruction: 95 didactic courses and 32 clerkships. The number of CAM offerings per school ranged from 1 to 8 . At 35 schools (26.9\%) a single CAM course or clerkship was offered. Three or more courses were offered at a small number of schools $(14,10.8 \%)$. There was no evidence of any CAM instruction at 59 schools representing nearly half (45.4\%) of US medical schools. The majority of the CAM offerings (70.9\%) were didactic courses offered as electives. Only five schools required a CAM course, a single school required a CAM clerkship in addition to an elective course (see Table 1).

Table I Integrative medicine courses and clerkships

\begin{tabular}{lllll}
\hline & Required & Elective & Total & (\%) \\
\hline Course & 5 & 90 & 95 & 74.8 \\
Clerkship & 1 & 31 & 32 & 25.2 \\
Total & 6 & 121 & 127 & \\
$(\%)$ & 4.7 & 95.3 & & 100.0 \\
\hline
\end{tabular}




\section{Topics}

Because a broad range of topics fall under the umbrella term of CAM specific information on the content, objectives, and assessment methods of the 127 courses or clerkships was explored. From the course and clerkship listings, 15 specific topics were identified ranging from whole systems medicine to individual alternative therapies (see Table 2). The most common course topic was a general introduction to CAM in courses that described a survey approach of different CAM topics. This flexible syllabus frequently listed course topics as "to be determined" presumably based upon guest speaker availability.

Among the specific CAM topics identified were professions (ie, therapies requiring a license to practice in some US states) such as acupuncture, chiropractic, massage, naturopathy, osteopathy, and creative arts therapies. Additional therapies that would require some level of training to perform a treatment (yoga, Tai Chi, meditation, biofeedback, and hypnosis) were listed. Yet, relatively accessible approaches like visualization and breathing techniques were not found at all. Herbs, an important part of naturopathic practice, were included in courses more frequently than naturopathy. Despite the popularity of energy therapies, like Reiki, Therapeutic Touch, and Healing Touch in nursing, none of these, nor the topic of energy medicine in general, were popular topics. Topics that are not typically designated as alternative therapies - osteopathy, creative arts therapies, spirituality, and humanism - were frequently noted.

Table 2 Topics included in IM courses

\begin{tabular}{|c|c|c|}
\hline Topic & $\begin{array}{l}\text { Number of courses } \\
\text { containing topic }\end{array}$ & $\%$ \\
\hline CAM & 40 & 31.5 \\
\hline Traditional medicine & 25 & 19.7 \\
\hline Acupuncture & 22 & 17.3 \\
\hline Meditation & 21 & 16.5 \\
\hline Spirituality & 18 & 14.2 \\
\hline Herbs & 17 & 13.4 \\
\hline Massage & 14 & 11.0 \\
\hline Energy medicine & 14 & 11.0 \\
\hline Chiropractic & 10 & 7.9 \\
\hline Osteopath & 10 & 7.9 \\
\hline Yoga & 9 & 7.1 \\
\hline Biofeedback & 7 & 4.7 \\
\hline Hypnosis & 5 & 3.9 \\
\hline Creative arts therapies ${ }^{a}$ & 5 & 1.6 \\
\hline Tai Chi & 2 & 3.9 \\
\hline Naturopathy & 2 & 1.6 \\
\hline
\end{tabular}

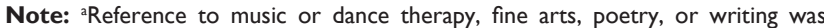
indicated in the course topics.

Abbreviations: IM, integrative medicine; CAM, complementary and alternative medicine.

\section{Self-care versus patient-care}

Within the course content, emphasis on the student's health or well-being was referenced more frequently than activities involving patient care. Personal growth, the sampling of CAM, or use of CAM techniques to promote self-care for the student was part of 32 courses (25.2\%). This was presented similarly in both didactic courses and clerkships. Individualized instruction permitting the student to identify and study a topic of interest was used for 16 courses (12.6\%). Additionally, recommendations for, or opportunities to receive a CAM treatment were described in 21 courses (16.5\%). Conversely, references to patient care such as performing a holistic assessment or developing a patient treatment plan including CAM was only referenced in 14 clerkship listings (11.0\%).

\section{Inter-professional education}

The existence of licensed professions in CAM presents the opportunity for inter-professional education. Yet only 14 courses $(11.0 \%)$ referenced an inter-professional instruction and nine (7.1\%) described an opportunity to observe a CAM practitioner working in a clinical setting. An additional 65 entries referenced observation or shadowing a provider, but these activities did not specifically state whether this would include interaction with a CAM practitioner. Only four courses (3.2\%) specifically referenced the topic of communication with CAM practitioners. Two listings referenced assisting with a treatment and two more performing a treatment while supervised. However, none of these explicitly stated which CAM therapy the student would be using in the treatment.

\section{Instruction and assessment}

Methods of instruction included lectures for 82 courses (64.6\%), assigned readings for $81(63.8 \%)$, and observing demonstrations of a CAM treatment for 76 (59.8\%). Receiving a CAM treatment or sampling a CAM therapy in some manner were referenced in 42 courses (33.1\%), but for only 17 of these courses was the therapy used to treat a health-related problem. Methods of assessment included presentations $(36,28.3 \%)$, journaling or reflection essay $(29,22.8 \%)$, research paper $(22,17.3 \%)$, or written examinations $(21,16.5 \%)$. A written case study or patient treatment plan was used in 28 courses (22.8\%); nearly as often as the requirement for the medical student to develop a personal self-care plan $(29,22.8 \%)$.

\section{Discussion}

Course and curriculum information was available for nearly all of the medical schools making this the most objective and 
comprehensive report to date. Although CAM has crept back into medical education, fewer medical schools were found to have CAM courses than reported in previous surveys. This suggests there is either less enthusiasm for CAM at present or there was potential bias in terms of over-reporting in previous surveys. Because the focus of the present analysis was course description, inclusion of CAM topics in other types of courses (ie, vertical integration of CAM in the curriculum) would not have been captured if indeed it exists.

Little consistency was noted in the topics covered, regardless of whether the offering was a course or clerkship. CAM course offerings were primarily didactic courses suggesting that understanding the theories and foundations of CAM therapies may be perceived as important and presented as such. However, the flexible syllabus approach also suggests that the topic matter may depend solely on available presenters or guest speakers indicating a lack of stability in topic matter. Despite the designation of some CAM courses as courses and others as clerkships, a blurring was seen: some didactic courses included experiential activities and some clerkships included didactic instruction. Exploration of the methods of instruction and assessment in such cases did not reveal discernable differences between the types of courses.

A core set of competencies in integrative medicine, including CAM has been proposed, ${ }^{9}$ yet a lack of a cohesive approach to the topic of CAM was found in this analysis. The prevalence of general CAM courses suggests that the aim of such courses may be to provide broad knowledge about patient health care choices. Beyond that it is unclear how medical students will be expected to use knowledge from these courses in patient care other than potentially referring patients to CAM providers. CAM techniques that could potentially be used by physicians in any area of practice, such as visualization, reflection, or breathing exercises, were not common. This suggests that the purpose of CAM courses is not to teach medical students skills that they can incorporate into patient care, but instead serves a more general learning purpose.

The sampling of CAM treatments as part of courses and frequent inclusion of self-care raises potential questions about liability in terms of student safety. When CAM is described as a treatment, that implies a therapeutic application to a sign, symptom, or medical condition. However, none of the courses mentioned criteria for which a medical student should receive a CAM treatment. This introduces potential for bias. A CAM therapy may be perceived as benign if the medical student has no way to measure effectiveness in relation to a sign, symptom, or condition. While CAM approaches, such as yoga or Tai Chi may play a role in health promotion/disease prevention, the notion that CAM courses provide an avenue for self-care for medical students is particularly troubling when the therapies are not offered as preventive care to patients served by the US health care system.

The opportunity for inter-professional education between medical students and students in the CAM professions seems important. Multiple references were noted for observations of a CAM treatment, but it was not clear what this would entail. Little description was provided about the role of inter-professional education. Therefore it was not possible to explore potential consistency in these experiences for medical students.

Methods of instruction frequently drew upon lectures and readings, indicating recognition of the differences in the theories and foundations upon which CAM therapies are based compared to biomedicine. The emphasis on assessment using self-care plans, journaling, and self-reflection suggested that the focus of the courses to meet personal health needs was not isolated to a few courses or institutions. This raises concern about whether the course content is taken seriously in terms of its potential for patient care. This is particularly important in the absence of long-term impact of CAM courses on patient health outcomes.

A limitation of this analysis is the reliance on publicly available information because all references to CAM in the medical curriculum may not have been captured in the data. It is conceivable that CAM topics may be discussed informally or vertically integrated in the curriculum. However since course information was available from nearly every US medical school, the reliance on objective data suggests that previous surveys over-reported the inclusion of CAM in the formal medical school curriculum.

Future research should examine how information learned in CAM courses and clerkships is ultimately utilized by physicians in practice. Issues related to potential liability when students sample CAM therapies in experiential courses should be closely examined. Focus on patient-relevant outcomes of CAM courses may be needed to rationalize the continued inclusion of CAM in the medical school curriculum.

\section{Funding}

This project was funded in part by a Rutgers University School of Health Related Professions Summer Student Research Grant.

\section{Disclosure}

The authors have no conflicts of interest to disclose. 


\section{References}

1. Duffy TP. The Flexner Report- 100 years later. Yale J Biol Med. 2011;84(3) 269-276.

2. Whorton JC. Nature cures: The History of Alternative Medicine in America. New York, NY: Oxford University Press; 2002.

3. Eisenberg DM, Davis RB, Ettner SL, et al. Trends in alternative medicine use in the United States, 1990-1997: results of a follow-up national survey. JAMA. 1998;280(18):1569-1575.

4. Eisenberg DM, Kessler RC, Foster C, Norlock FE, Calkins DR, Delbanco TL. Unconventional medicine in the United States. Prevalence, costs, and patterns of use. N Engl J Med. 1993;328(4):246-252.

5. Lie D, Boker J. Development and validation of the CAM Health Belief Questionnaire (CHBQ) and CAM use and attitudes amongst medical students. BMC Med Educ. 2004;4:2.

6. Schneider CD, Meek PM, Bell IR. Development and validation of IMAQ: Integrative Medicine Attitude Questionnaire. BMC Med Educ. 2003; $3: 5$.

7. Benjamin PJ, Phillips R, Warren D, et al. Response to a proposal for an integrative medicine curriculum. JAltern Complement Med. 2007;13(9): 1021-1033.

8. Gaster B, Unterborn JN, Scott RB, Schneeweiss R. What should students learn about complementary and alternative medicine? Acad Med. 2007;82(10):934-938.
9. Kligler B, Maizes V, Schachter S, et al. Core competencies in integrative medicine for medical school curricula: a proposal. Acad Med. 2004;79(6):521-531.

10. Adams KE, Cohen MH, Eisenberg D, Jonsen AR. Ethical considerations of complementary and alternative medical therapies in conventional medical settings. Ann Intern Med. 2002;137(8):660-664.

11. Wetzel MS, Eisenberg DM, Kaptchuk TJ. Courses involving complementary and alternative medicine at US medical schools. JAMA. 1998;280(9):784-787.

12. Brokaw JJ, Tunnicliff G, Raess BU, Saxon DW. The teaching of complementary and alternative medicine in US medical schools: a survey of course directors. Acad Med. 2002;77(9):876-881.

13. Brauer JA, El Sehamy A, Metz JM, Mao JJ. Complementary and alternative medicine and supportive care at leading cancer centers: a systematic analysis of websites. J Altern Complement Med. 2010;16(2): 183-186.

14. Marcus DM, McCullough L. An evaluation of the evidence in "evidence-based" integrative medicine programs. Acad Med. 2009;84(9): 1229-1234.
Advances in Medical Education and Practice

\section{Publish your work in this journal}

Advances in Medical Education and Practice is an international, peerreviewed, open access journal that aims to present and publish research on Medical Education covering medical, dental, nursing and allied health care professional education. The journal covers undergraduate education, postgraduate training and continuing medical education

\section{Dovepress}

including emerging trends and innovative models linking education, research, and health care services. The manuscript management system is completely online and includes a very quick and fair peer-review system. Visit http://www.dovepress.com/testimonials.php to read real quotes from published authors.

Submit your manuscript here: http://www.dovepress.com/advances-in-medical-education-and-practice-journal 